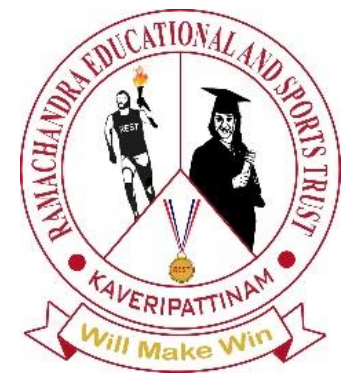

Recent trends in Management and Commerce

Vol: 2(1), 2021

REST Publisher

ISBN: 978-81-936097-6-7

Website: $\underline{\text { http://restpublisher.com/book-series/rmc/ }}$

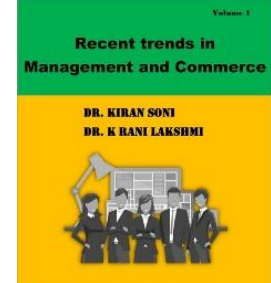

\title{
A New Genre of Inventory Models with Elements of Social Commerce and Pertinent Outlays
}

Nivetha Martin, Renee Miriam. M

Department of Mathematics, Arul Anandar College (Autonomous), Karumathur

Corresponding Author: reneemiriamm@gmail.com

\begin{abstract}
The objective of developing inventory models is going through a series of paradigm shift from optimizing conventional to contemporary costs factors. New-fangled inventory models are evolved in recent times with the inclusion of new types of costs to the dynamic and comprehensive costs parameters of the earlier inventory models. The advancement in the domain of technology has enriched the accessibility of the manufacturing sectors to marketing, distribution electronic and social commerce channels. This has made the managerial delegates of all scales of business levels to drift towards the strategical plan of incorporating the elements of social commerce to their inventory management systems. This research work puts forth the conceptual development of another class of inventory models with the components of social commerce and the associated costs of using the medium of social networks in marketing, customer relationship managements, product research, advertising, product tracking and distribution. A social commerce inventory model of deterministic nature is proposed in this paper to kick start a new genre of inventory modelling.
\end{abstract}

Keywords: Social commerce, inventory model, new types of costs, contemporary models, costs minimization

\section{Introduction}

Traditional Commerce relates to trade and auxiliaries to trade. 'Trade' is used to denote exchange of commodities in physical presence and 'Auxiliaries to trade' are banking, ads, transportation, insurance etc., The technological upscale has made the system of trading undergo a series of changes in the conventional processes of product exchange, as an outcome of it, in 1991, e-commerce came into existence when Internet was extended for commercial use. It refers to buying and selling of goods with the aid of Internet [1]. The inception of COVID-19 impeded brick-and-mortar businesses, but it opened new horizons of online business. Specially, it became a catalyst for social commerce to grow into a juggernaut. The dissimilarity between e-commerce and social commerce is that the former refers to the encounter of shopping via a website or an app and the latter refers to buying and selling of goods and services directly through social media platform. Social commerce is an intact process. Starting from product search and exploring new commodities till the checkout process we can do everything through social media platform. It is a brand friendly system. Contrast to e-commerce where the user while searching for a single product is flooded by results from different brands, in social commerce every brand can effectively be personalized and highlighted which in fact brings a spotlight over them. The targeted audience in social commerce business are mainly Gen Z, Millennials, influencers, enthusiastic social media users and so on. With the commencement of pandemic, left with no option, government-imposed lockdown enforced people to stay indoors. Boredom made people extend their online usage time. It was a good time for companies to start expanding their business by selling their goods online in social media platform as social media platforms allows blending of shopping experience and online connections. Traditional offline shopping and social commerce are in a way alike. In offline shopping, people generally shop with their family or friends. In social commerce, a person can search and find products, share them with friends and family for feedbacks through online. As the entire shopping process can be completed very easily within social media platforms without any navigation, it is an ideal situation for marketer and customers. Facebook, Instagram, snapchat, WhatsApp and twitter are some of the major platforms of social commerce. Instagram has become the king amongst social commerce platforms in recent times. Facebook in the year 2016, allowed marketing with only minimal options [2]. Now they have revamped it by launching Facebook shops where businesses can create their own shop and get to customize it with pictures, vibrant colors and fonts, handpick their catalog and present it to their customers. It helps them to attach with their potential customers. The customers are enlightened about launch of new products and any other offers. Tiktok has been working on e-commerce since 2019 using basic links within clips [3]. Then it started budding by the development of its own platform selling tools, livestream shopping events and incorporation with Shopify to display product's in-stream ads. Tiktok launched 'Small Gestures' option which enabled users to ship free virtual gifts from a range of business partners within the app. Tiktok has recently revealed about its upcoming launch, Promo tiles and Showcase tiles. 'Promo tiles' enables businessman to add customizable sales and promotional alerts imposed on their video clips and 'Showcase Tiles' enables creators to personally promote products in their uploads. Following the path steps of Tik Tok, a predominant video app, Instagram launched its own 15second video function named Reels. Reels not only allows you to share content but allows you to shop products. Creators can exhibit their talent and can conquer customers. People can also use the predominant shop tab available. When a user 
clicks it, he is directed towards an immersive full screen storefront. Survival of small-scale businesses, craft shops are influenced by this new shopping experience. Businesspeople can tag their products through their post or Stories with the help of Instagram Shopping tags. Detailed description of the product can be displayed. Instagram has recently developed a new tab 'Drops'. Drops exhibit new releases from trending designers and retailers. Feed of images, videos and animation are displayed to the users indicating arrival of new products and when the drops are live, users can click and purchase them immediately. Imminent drops are featured in the 'drops' feed with live countdown until launch. WhatsApp acts as a tool to support Facebook and Instagram Shops. SME can design a Catalog in Business tool option Under Settings and upload highly appealing products and simplify ordering. WhatsApp has launched Shopping button and Cart recently. Shopping button allows the customer to view the Catalog and Cart option allows the customer to select multiple products and can send them as a message to the marketer. WhatsApp also allows to add Business website address so that the interested customers can visit the website quickly. Recently, Facebook pay allows payment in WhatsApp. For larger businesses, WhatsApp's API supports automated sales, and many leading companies are using this feature. Customers can just "Say hi" to get in touch with the marketers to ask questions and buy their favorite products through automated conversational workflows and bots. Pinterest 'complete the look' feature provides visually reconcilable results in Fashion and Home Decor Pins. Recently, it has initiated 'buyable pins which allows users to shop directly on Pinterest without leaving the platform. There are 600 lakh buyable pins, and it is about to grow over time [4]. Meesho the most predominant social commerce platform allows to start business with zero investment. Women entrepreneurs are the superior contributors of online reselling, especially housewives. These resellers usually sell fashion, furnishing, home appliances market products. As it integrates with Instagram, WhatsApp and Facebook it enables them to monetize their huge social network such as family, friends and neighbors. As online commerce can be done through chats, videos and live in-app telecast in their respective local language it gave abundance of opportunities to micro-entrepreneurs. Meesho is planning to compete with established online retailers by selling grocery products and fastmoving consumer goods. Social commerce as a whole is growing into new levels and certainly it is making great changes in the entire process of product production. Social Commerce help to acquire more customers and many people have become entrepreneurs. Marketers gain customers from different part of the world. As social commerce helps in getting feedback from customers, it acts as a free tool to understand customers mind set and priorities. In contrary to previous commerce techniques, social commerce allows even small businesses to showcase their product without much difficulty and allows them to establish their brand name. Every new change and launch of new products can be readily displayed to customers. Social commerce also allows to target specific group of people and gain more profit will lower customer acquisition cost. Social commerce aids Modern consumers when they crave for trendy, personalized and unique products. The World is changing. Consumers can shop anywhere and can explore different products. Even a consumer residing in one part of the world can shop products available in another part of the world. A consumer can shop from anywhere and anytime. Social commerce provides the ability to compare the cost of products which helps a person to purchase products which they like at low cost. Even the products which consumers considers to be incredibly special are purchased online. Orders to design wedding costume in online are quite common nowadays, and measurements are taken in video call. The practice of gifting online has tremendously increased. Product reviews are available online and people get to know more about the product and can make decisions to buy. Product Demonstration is readily available which tend people to purchase more products with ease and attracts naive customers. Unlike the previous commerce techniques, feedbacks and queries are handled properly by retailers due to the fear of losing more customers by spread of word online. Businesses are more conscious and serious about their customers after the commencement of Social Commerce. According to a new report titled, 'The Future of Commerce in India - the rise of social commerce', released by Bain and Company the Gross Merchandise Value (GMV) of India's social commerce sector, is $\$ 1.5$ to $\$ 2$ billion GMV market today, can rise to $\$ 16$ to $\$ 20$ billion in another five years, and to $\$ 60$ to $\$ 70$ billion by 2030 . That is within ten years span, India's social commerce sector will be twice the size of the current e-commerce market and formats ranging from conversational commerce on chat platforms to video-led commerce, or a lively social reseller community. Social commerce is $21^{\text {st }}$ century shopping mall [5]. Owing to pandemic, Social Commerce businesses and consumers had great shopping experience and it has only increased the expectation from both ends. The Customer and entrepreneur's relationship will become stronger and more transparent in the future. Contemporary Social commerce is just the beginning of a technology driven marketing and will thrive gloriously in the days to come. The evolution in the domain of technology has enriched the accessibility of the manufacturing sectors to marketing, distribution electronic and social commerce channels. Managerial delegates of all scales of business levels drift towards the strategical idea of including the elements of social commerce to their inventory management systems with the incorporating new types of costs to the dynamic and comprehensive costs parameters of the earlier inventory models. Some of the cost incurred by Conventional commerce are set up cost, holding cost, Internet cost, Advertisement cost. The subsequent inventory model includes the new cost parameters of using social commerce for marketing. There are inventory models that discusses the costs and impacts of advertising on product propagation and customer acquisition. To mention a few, Ritha et al [6] proposed Economic Production Inventory model with internet advertising and its associated cost to acquire worldwide residing customers, Perleche et al [7] proposed a bid-optimization technique for advertising companies, Aggarwal et al [8] developed a model based on dynamic advertising expenditure demand, Carter et al [9] developed a system that maximized click-through rate of advertisement. The inventory models were extended with the inclusion of recent types of technology and its pertinent costs. Based on such developments of inventory modelling and the emergence of social commerce at recent times along has paved the origin of new genre of social commerce inventory models with the incorporation of new costs of consumer networking, consumer acceptability, product promotion costs, payment provision, outsourcing, social media management, social media advertising, strategy development, strategy management, trend analyst and advisor. 


\section{Model Development}

Let us consider an inventory production system with the following costs parameters such as Consumer networking costs, Consumer acceptability costs, Product promotion costs, Payment provision costs, Outsourcing costs, social media management Costs, Social media advertising costs, Strategy development costs, Strategy management costs, Trend Analyst and Advisor cost.

The notations given below are used throughout the paper.

$\mathrm{P}=$ Production rate per cycle,

$\mathrm{D}=$ Uniform demand rate per cycle,

$\mathrm{C}_{1}=$ Constant carrying cost or holding cost per unit quantity per unit time,

$\mathrm{C}_{3}=$ Fixed ordering cost or set up cost per order (or production run).

The inventory situation is illustrated in figure.

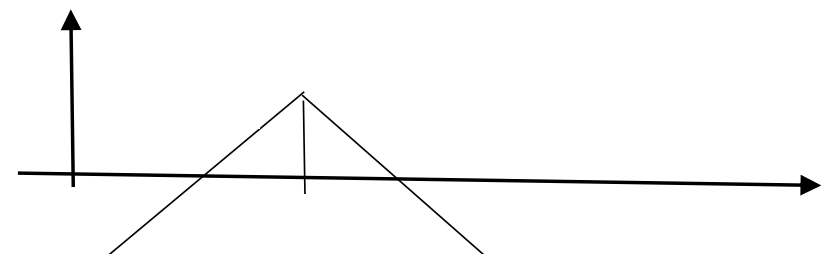

During the tirst scheduliıg |perıud $\mathrm{T}$, proxucuon starts just after $\mathrm{t}=0$ and continues up to $\mathrm{t}=\mathrm{t}_{1}$. Let the stock reaches a level $\mathrm{I}_{\mathrm{MAX}}$. Production is now stopped. The inventory reaches zero level at $\mathrm{t}=\mathrm{T}$ and no shortages are permitted.

If $\mathrm{q}(\mathrm{t})$ represents the inventory level at time $\mathrm{t} \in[0, \mathrm{~T}]$, so the differential equation for the instantaneous inventory $\mathrm{q}(\mathrm{t})$ at any time $t$ over $[0, T]$ is given by

$$
\begin{aligned}
& \frac{\mathrm{dq}(\mathrm{t})}{d t}=\mathrm{P}-\mathrm{D} \quad \text { for } \quad 0 \leq \mathrm{t} \leq \mathrm{t}_{1} \\
& =\mathrm{D} \text { for } \mathrm{t}_{1} \leq \mathrm{t} \leq \mathrm{T}
\end{aligned}
$$

With initial condition $\mathrm{q}(0)=0$

And boundary conditions $q(T)=0$.

Let $\mathrm{q}\left(\mathrm{t}_{1}\right)=\mathrm{I}_{\mathrm{MAX}}$

$\mathrm{Q}(\mathrm{t})=(\mathrm{P}-\mathrm{D}) \mathrm{t} \quad$ for $\quad 0 \leq \mathrm{t} \leq \mathrm{t}_{1}$

Solving (2) with (3), we get

$\mathrm{Q}(\mathrm{t})=-\mathrm{DT}+\mathrm{DT}$ for $\mathrm{t}_{1} \leq \mathrm{t} \leq \mathrm{T}$

Using (5) in (5) and (6), we get

$$
\begin{aligned}
\mathrm{I}_{\mathrm{MAX}} & =(\mathrm{P}-\mathrm{D}) \mathrm{t}_{1} & & (8) \\
& =\mathrm{D}\left(\mathrm{T}-\mathrm{t}_{1}\right) & & (9) \\
\therefore \mathrm{t}_{1} & =\frac{\mathrm{Imax}}{P-D}, & & \mathrm{~T}-\mathrm{t}_{1}=\frac{\text { Imax }}{D}
\end{aligned}
$$

And adding, we get $\mathrm{T}=\mathrm{I}_{\max }\left(\frac{1}{P-D}+\frac{1}{D}\right)$

$\therefore$ Holding cost $(\mathrm{HC})=\mathrm{C}_{1}\left[\int_{0}^{t_{1}} q(t) d t+\int_{t_{1}}^{T} q(t) d t\right]$

$$
\begin{aligned}
= & \mathrm{C}_{1}\left[(\mathrm{P}-\mathrm{D}) \frac{t_{1}^{2}}{2}+\mathrm{D} \frac{\left(T-t_{1}\right)^{2}}{2}\right] \\
& =\frac{C_{1}}{2}\left(1-\frac{D}{P}\right) D T^{2}[\mathrm{using}(8),(9),(10)]
\end{aligned}
$$

Total Cost $(\mathrm{TC})=$ Set up cost $\left(\mathrm{C}_{3}\right)+$ Holding cost $\left(\mathrm{C}_{1}\right)+$ Consumer networking costs $(\mathrm{n})+$ Consumer acceptability costs $(\mathrm{c})$

+ Product promotion costs $(\mathrm{p})+$ Payment provision costs $(\mathrm{b})+$ Outsourcing costs $(\mathrm{o})+$ Social media management Costs $(\mathrm{m})$ + Social media advertising costs (a) + Strategy development costs (d) + Strategy management costs (s) + Trend Analyst and Advisor cost ( $\mathrm{t}$ )

$=C_{3}+\frac{C_{1}}{2}\left(1-\frac{D}{P}\right) D T^{2}+n+c+p+b+o+m+a+d+s+t$

Total Average Cost (TAC)

$=\frac{1}{T}\left[C_{3}+\frac{C_{1}}{2}\left(1-\frac{D}{P}\right) D T^{2}+n+c+p+b+o+m+a+d+s+t\right]$

$=\frac{C_{3}}{T}+\frac{C_{1}}{2}\left(1-\frac{D}{P}\right) D T+\frac{n}{T}+\frac{c}{T}+\frac{p}{T}+\frac{b}{T}+\frac{o}{T}+\frac{m}{T}+\frac{a}{T}+\frac{d}{T}+\frac{s}{T}+\frac{t}{T}$

So the classical EPQ model is

Min TAC $(\mathrm{T})=\frac{C_{3}}{T}+\frac{C_{1}}{2}\left(1-\frac{D}{P}\right) D T+\frac{n}{T}+\frac{c}{T}+\frac{p}{T}+\frac{b}{T}+\frac{o}{T}+\frac{m}{T}+\frac{a}{T}+\frac{d}{T}+\frac{s}{T}+\frac{t}{T}$

Such that $\mathrm{T}>0$.

Solving (14), we can show that TAC (T) will be minimum for

$T^{*}=\sqrt{\frac{2\left(C_{3}+n+c+p+b+o+m+a+d+s+t\right)}{C_{1} D\left(1-\frac{D}{P}\right)}}$ and

$T A C\left(T^{*}\right)=\sqrt{2 C_{1}\left(C_{3}+n+c+p+b+o+m+a+d+s+t\right) D\left(1-\frac{D}{P}\right)}$ 


\section{Conclusion}

In this paper, a new genre of inventory model with the components of social commerce and the associated costs of using it has been proposed. This is a hypothesized inventory model and can act as a foundation for the upcoming inventory models.

\section{References}

1. https://www.ecommerce-land.com/history_ecommerce.html

2. https://www.pymnts.com/news/social-commerce/2021/facebook-lays-out-its-vision-for-the-future-of-commerce/

3. https://www.socialmediatoday.com/news/tiktok-moves-to-the-next-stage-of-ecommerce-testing-a-key-shift-for-the$\mathrm{pl} / 600005 /$

4. https://lab3web.com/instagram-pinterest-new-social-commerce-sites/

5. http://www.businessworld.in/article/Social-Commerce-The-Next-Frontier-Of-Online-Commerce-In-India-Has-ThePotential-To-Reach-60-To-70-Billion-In-Revenue-By-2030/10-12-2020-352208/

6. Ritha, W., \& Martin, N. (2014). Economic Production Inventory model with the associated costs of internet advertising to acquire customers residing worldwide. International Journal of Computers and Technology, 12(9), 3921-3926.

7. Perlich, C., Dalessandro, B., Hook, R., Stitelman, O., Raeder, T., \& Provost, F. (2012, August). Bid optimizing and inventory scoring in targeted online advertising. In Proceedings of the 18th ACM SIGKDD international conference on Knowledge discovery and data mining (pp. 804-812).

8. Aggarwal, K. K., \& Kumar, A. (2013). An inventory decision model for new products when demand depends on dynamic advertising expenditure. International Journal of Logistics Systems and Management, 15(4), 424-444.

9. Chickering, D. M., \& Heckerman, D. (2003). Targeted advertising on the web with inventory management. Interfaces, 33(5), 71-77.

10. Das, A. K., \& Roy, T. K. (2017). Fractional order generalized EPQ model. International Journal of Computational and Applied Mathematics, 12(2), 525-536.

11. Carter, J. R., \& Ferrin, B. G. (1996). Transportation costs and inventory management: Why transportation costs matter. Production and Inventory Management Journal, 37(3), 58. 